\title{
Prediction of Moisture Migration and Pore Pressure Build-up in Concrete at High Temperatures
}

\author{
Y. Ichikawa ${ }^{1)}$ and G. L. England ${ }^{2)}$ \\ 1) Kajima Corporation, Japan \\ 2) Imperial College of Science, Technology and Medicine, United Kingdom
}

\begin{abstract}
Prediction of moisture migration and pore pressure build-up in non-uniformly heated concrete is important for safe operation of concrete containment vessels in nuclear power reactors and for assessing the behaviour of fire-exposed concrete structures. (1) Changes in moisture content distribution in a concrete containment vessel during long-term operation should be investigated, since the durability and radiation shielding ability of concrete are strongly influenced by its moisture content. (2) The pressure build-up in a concrete containment vessel in a postulated accident should be evaluated exactly in order to determine whether a venting system is necessary between liner and concrete to relieve the pore pressure. (3) When concrete is subjected to rapid heating during a fire, the concrete can suffer from spalling due to pressure build-up in the concrete pores.

This paper presents a mathematical and computational model for predicting changes in temperature, moisture content and pore pressure in concrete at elevated temperatures. A pair of differential equations for one-dimensional heat and moisture transfer in concrete are derived from the conservation of energy and mass, and take into account the temperature-dependent release of gel water and chemically-bound water due to dehydration. These equations are numerically solved by the finite difference method. In the numerical analysis, the pressure, density and dynamic viscosity of water in the concrete pores are calculated explicitly from a set of formulated equations.

The numerical analysis results are compared with two different sets of experimental data: (a) long-term (531 days) moisture migration test under a steady-state temperature of $200^{\circ} \mathrm{C}$, and (b) short-term $(114$ minutes) pressure build-up test under transient heating. These experiments were performed to investigate the moisture migration and pressure build-up in the concrete wall of a reactor containment vessel at high temperatures. The former experiment simulated the effect of long-term steady-state liner temperature during normal operation, and the latter simulated a situation where an accident resulted in sudden, short-term heating to approximately $400^{\circ} \mathrm{C}$.

Finally, concrete spalling is simulated by the numerical analysis; and the results show how the moisture content and pore pressure distributions in concrete exposed to fire change with time and temperature. The numerical analysis can predict the time, position and temperature at which spalling occurs.
\end{abstract}

\section{INTRODUCTION}

Since experiments on concrete at high temperatures are very expensive, estimating moisture migration and pressure build-up in concrete by numerical analysis can yield benefits of economy. It would be desirable, therefore, to develop a heat and moisture transfer model for reliable prediction of changes in temperature, moisture content and pore pressure, while also taking account of the changing properties of concrete with time and/or temperature. Bazant and Thonguthai [1], [2] developed a one-dimensional and two-dimensional finite element method for predicting pore pressure in heated concrete by solving a pair of heat and moisture transfer equations. Ahmed and Hurst [3], [4], [5] proposed a mathematical model for simulating the coupled heat and mass transfer in concrete exposed to elevated temperatures. They developed a set of three coupled differential equations, taking into account the conservation of mass, momentum and energy, and including the effects of evaporation and dehydration processes. England and Khoylou [6], [7] proposed a numerical model with two equations for heat and moisture flow. Moisture flow consisted of two different forms: pressure-induced flow and diffusion-based flow.

\section{NUMERICAL MODELLING}

A mathematical and computational model has been set up to predict heat and moisture transfer and pore pressures [8]. This model has the advantage of being able to accurately and simply calculate the pressure, density and dynamic viscosity of water in concrete pores by the formulated equations [9], [10], [11]. Accordingly, changes in moisture content and pressure distribution during heating can be predicted precisely. 


\section{Modelling of Concrete Components}

Concrete is a porous material, as shown in Fig. 1-(a). Figure 1-(b) schematically shows concrete structure and the volumetric proportions of concrete components. Hardened concrete consists of solid products and pores. The solid products consist of aggregate, cement (hydrated or unhydrated), chemically-bound water and gel water. The pores are fully or partially filled with free water. The free water can move through the pores.

The initial conditions for the moisture transfer analysis are the mass of the three forms of water (i.e. chemicallybound water $\left(m_{\mathrm{nw}}\right)$, gel water $\left(m_{\mathrm{gw}}\right)$, free water $\left.\left(m_{\mathrm{fw}}\right)\right)$ and the volume of pores $\left(V_{\mathrm{p}}\right)$. These components depend on the water/cement ratio $(w / c)$, the mix water content $\left(m_{\mathrm{tw}}\right)$, the air content $\left(V_{\text {air }}\right)$ and the degree of hydration $\left(\alpha_{\mathrm{h}}\right)$.

The quantity of chemically-bound water can be determined as non-evaporable water content $\left(m_{\mathrm{nW}}\right)$, and the total quantity of free water and gel water can be determined as evaporable water content $\left(m_{\text {ew }}\right)$. As temperature rises, gel water and chemically-bound water contained in the solid products are released into the pores by dehydration, and these components are then added to the free water. Consequently, the pore volume increases where these components are released.

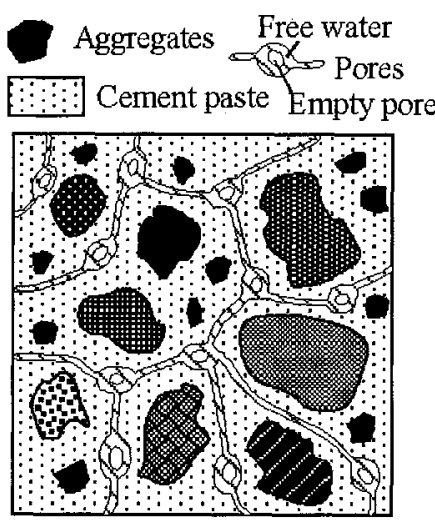

(a)

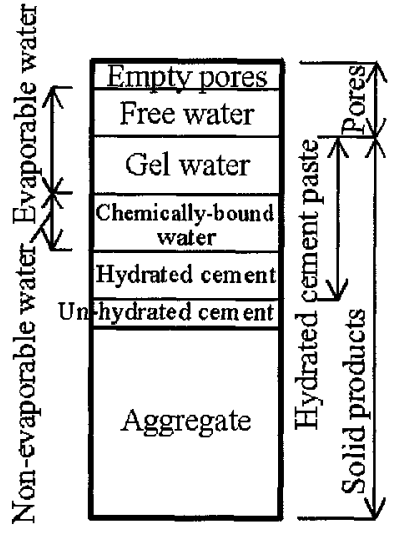

(b)
Figure 1 (a) Schematic description of concrete structure, and (b) volumetric proportions of concrete components.

\section{Differential Equations for Heat and Moisture Transfer Analysis}

The equation for heat transfer, governed by heat conduction, is given as:

$$
\rho_{\mathrm{con}} c \frac{\partial T}{\partial t}=\frac{\partial}{\partial x}\left(\lambda \frac{\partial T}{\partial x}\right)
$$

where $\rho_{\text {con }}, c, \lambda$ and $T$ are density, specific heat, thermal conductivity and temperature of concrete, respectively.
The equation for moisture transfer is given as:

$$
\begin{aligned}
\frac{\partial m_{\mathrm{fw}}}{\partial t}= & \frac{\frac{\partial}{\partial x}\left(k \frac{\rho_{\mathrm{fw}}}{\eta_{\mathrm{fw}}} \frac{\partial p}{\partial x}\right)}{p \text { pressure-induced flow }}+\frac{\partial}{\partial x}\left(D \frac{\partial m_{\mathrm{fw}}}{\partial x}\right) \\
& +\quad \frac{\frac{\partial}{\partial t}\left(m_{\mathrm{gw}-\mathrm{rel}}+m_{\mathrm{nw}-\mathrm{rel}}\right)}{\text { diffusion-based flow }} \\
& \text { release of gel water and chemically }- \text { bound water }
\end{aligned}
$$

where $m_{\mathrm{fw}}, k, D, p, \rho_{\mathrm{fw}}, \eta_{\mathrm{fw}}, m_{\mathrm{gw}-\text { rel }}$ and $m_{\mathrm{nw}-\text { rel }}$ are moisture content (mass of free water), permeability, diffusion coefficient of concrete, pressure, density, dynamic viscosity of free water, mass of released gel water and mass of released chemically-bound water, respectively.

Moisture transfer results from the combined effects of two mechanisms: (1) pressure-induced flow derived from Darcy's law and (2) diffusion-based flow derived from Fick's law. During heating, gel water and chemically-bound water are released from the cement paste into the concrete pores as free water. These extra water components are taken into account during the moisture transfer analysis.

\section{Pressure Build-up}

The moisture transfer leads to the creation of dry (A), wet (B), and saturated (C) zones in concrete. Generally, $T_{\mathrm{A}}>T_{\mathrm{B}}>T_{\mathrm{C}}$ close to the heat source. The corresponding pore pressures, $p_{\mathrm{A}}>p_{\mathrm{B}}>p_{\mathrm{C}}$ each change differently with time and generate the flow. The water properties are described schematically in Fig. 2, and show that water is in a compressed state in zone $(\mathrm{C})$ where $p_{\mathrm{C}}>p_{\text {svp }, T c}$. In the other zones, $p_{\mathrm{A}}<p_{\text {svp }, T \mathrm{~A}}$ and $p_{\mathrm{B}}=p_{\mathrm{svp}, 7 \mathrm{~s}}$. These pressures can be calculated using the equations developed by Saul and Wagner [9], [10].

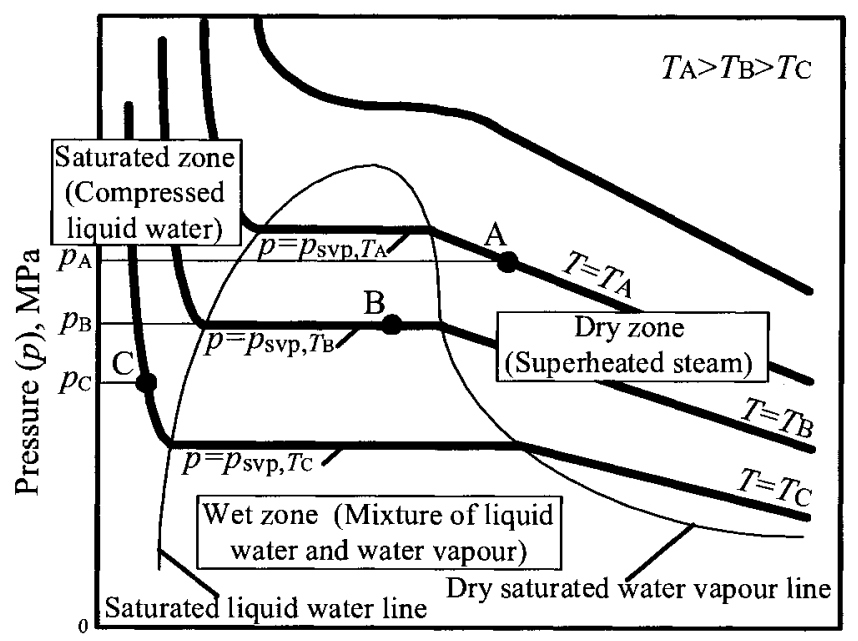

Specific volume $(v), \mathrm{m}^{3} \mathrm{~kg}^{-1}$

Figure 2 Pressure - specific volume relationship of water depending on temperature. 


\section{NUMERICAL SIMULATION}

The numerical results of the heat and moisture transfer analysis are compared with data from two sets of experiments performed to investigate the moisture migration and pressure build-up behaviour in the concrete wall of a reactor containment vessel at high temperatures. These experimental sets were as follows:

(1) Long-term (531 days) moisture migration test under a steady-state temperature crossfall; maximum temperature of $200{ }^{\circ} \mathrm{C}$.

(2) Short-term (114 mins) pressure build-up test under transient heating up to $400{ }^{\circ} \mathrm{C}$.

\subsection{Long-Term Moisture Migration}

Chapman's experiment [12], [13] simulated the effect of a long-term steady-state liner temperature during normal operation.

Figure 3-(a) shows a cylindrical concrete specimen with a length $(L)$ of $1.524 \mathrm{~m}$ and a diameter $(d)$ of $0.152 \mathrm{~m}$. This specimen was sealed on all faces except one end, which was exposed to the atmosphere. The mix proportions of the concrete used in the experiment are shown in Table 1. Heat was applied to the closed end and the curved surface to produce a steady-state temperature distribution throughout the simulated wall thickness, as shown in Fig. 3-(b). The temperatures at the hot surface $(x=0)$ and at the cold surface $(x=L)$ were $200^{\circ} \mathrm{C}$ and $76{ }^{\circ} \mathrm{C}$, respectively. The evaporable water content $\left(m_{\mathrm{ew}}\right)$ and pressure $(p)$ were measured throughout the 531-day duration of the experiment. Measuring positions were at 5 distances from the hot surface, as shown in Fig. 3-(a).

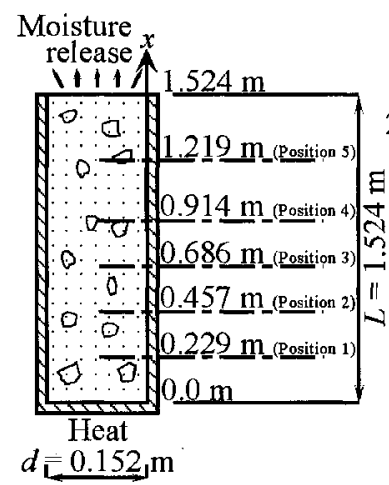

(a) Specimen

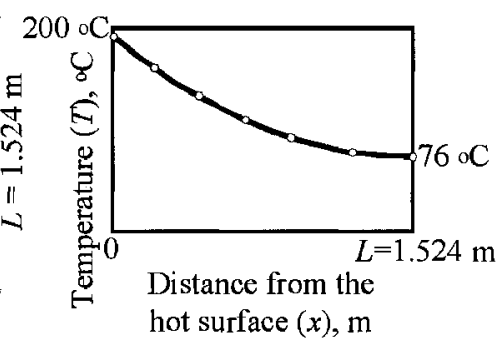

hot surface $(x), \mathrm{m}$
Figure 3 Test specimen and temperature distribution (Chapman [12], [13]).

Table 1 Mix proportions of Concrete (Chapman [12], [13]).

\begin{tabular}{|c|c|c|c|}
\hline $\begin{array}{c}\text { Cement } \\
(\mathrm{OPC})^{* 1}\end{array}$ & Sand $^{*^{2}}$ & $\begin{array}{c}\text { Coarse } \\
\text { aggregate }\end{array}$ & Water \\
\hline 1.0 & 2.67 & 4.0 & 0.6 \\
\hline
\end{tabular}

Water/cement ratio $(w / c)=0.60$.

Aggregate/cement ratio $(a / c)=6.67$.

* 1: OPC = Ordinary Portland Cement.

*2: Crushed limestone.
In order to simulate Chapman's experiment, the specimen is represented by a one-dimensional model of length $L=1.524 \mathrm{~m}$. The hot surface $(x=0)$ is sealed and the cold surface $(x=L)$ is unsealed. The input data for the numerical analysis are shown in Table 2.

Table 2 Input data for numerical analysis.

\begin{tabular}{|l|l|}
\hline \multicolumn{2}{|c|}{ Initial conditions } \\
\hline Mass of chemically-bound water $\left(m_{\mathrm{nw}}\right)$ & $63.7 \mathrm{~kg} \mathrm{~m}^{-3}$ \\
\hline Mass of gel water $\left(m_{\mathrm{gw}}\right)$ & $58.2 \mathrm{~kg} \mathrm{~m}^{-3}$ \\
\hline Mass of free water $\left(m_{\mathrm{fw}}\right)$ & $53.1 \mathrm{~kg} \mathrm{~m}^{-3}$ \\
\hline Volume of pores $\left(V_{\mathrm{p}}\right)$ & $0.0796 \mathrm{~m}^{3} \mathrm{~m}^{-3}$ \\
\hline \multicolumn{2}{|c|}{ Properties of concrete } \\
\hline Permeability $(k)$ & $4.0 \times 10^{-18} \mathrm{~m}^{2}$ \\
\hline Diffusion coefficient $(D)$ & $4.0 \times 10^{-9} \mathrm{~m}^{2} \mathrm{~s}^{-1}$ \\
\hline
\end{tabular}

Figure 4 compares simulated and experimental evaporable water content distributions in the concrete specimen at various heating times. Moisture in the hot region moves towards the cold region due to pressureinduced flow. Therefore, the evaporable water content near the hot surface gradually decreases and a dry zone appears. In the dry zone, the evaporable water content value is very small. The area of the dry zone increases with time. In the middle of the specimen, evaporable water content exceeds the initial evaporable water content. In this region, concrete

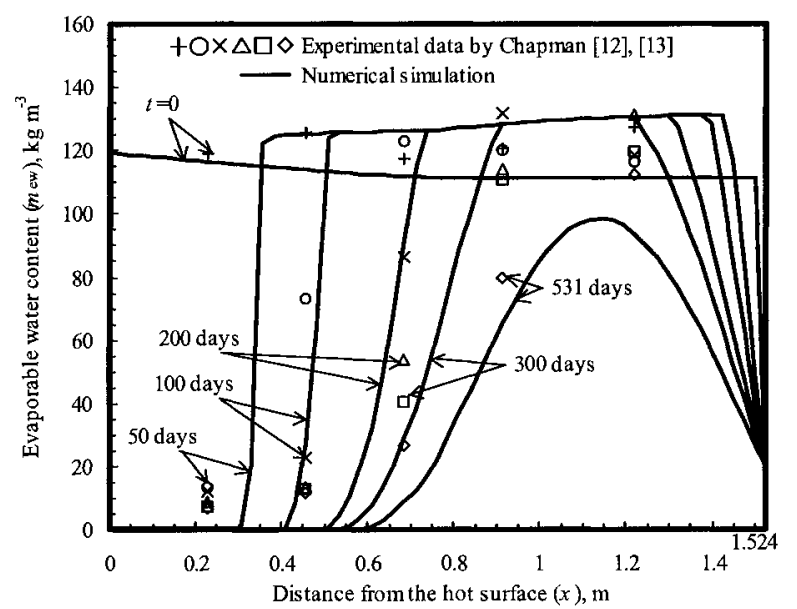

Figure 4 Comparison of simulated and experimental evaporable water content distributions at various times. 
pores are filled with water. This region is defined as a saturated zone. The saturated zone moves towards the cold surface with time. The numerical results qualitatively simulate these phenomena well.

Figure 5 compares simulated and experimental pressure distributions in the concrete specimen at various heating times. At the start of heating $(t=0)$, both numerical simulation and experimental data are equal to the saturation vapour pressure $\left(p_{\mathrm{svp}, T}\right)$. After the start of heating, pressure in the dry zone gradually decreases with time due to the loss of moisture. The dry zone can be identified in the figure because the pressure values are uniform and smaller than the saturation vapour pressure. The numerical results qualitatively simulate this phenomenon well. A saturated zone can also be identified in the figure, because the pressure distribution is greater than the saturation vapour pressure.



Figure 5 Comparison of simulated and experimental pressure distributions at various times.

\subsection{Short-Term Pressure Build-up}

Khan's experiment [14], [15] was performed to simulate the thermal shock problem caused by an accident in a Fast Breeder Reactor (FBR) in which hot sodium coolant makes contact with the metal liner of the concrete containment vessel subjected to sudden heating to $400{ }^{\circ} \mathrm{C}$.

Figure 6-(a) shows a cylindrical concrete specimen with a length $(L)$ of $0.34 \mathrm{~m}$ and a diameter $(d)$ of $0.105 \mathrm{~m}$. The test specimen was set up to simulate concrete in contact with a vessel liner at the liner-concrete interface. Since only short-term responses were sought, short specimens $(L=0.34$ m) were used. The concrete was contained in a thick cylindrical steel tube. The heated end was sealed with a stainless steel diaphragm (simulating the liner of a reactor containment vessel), and the other end incorporated a steel base plate. The mix proportions of the concrete used in the experiment are shown in Table 3. The diaphragm, located at one end of the concrete specimen contained in a cylindrical steel tube, was heated with molten lead preheated to $675^{\circ} \mathrm{C}$. The lead was retained as a molten pond and kept heated by means of supplementary heaters within the pond and around its containment. This procedure produced a sustainable concrete temperature at the position of the liner of approximately $400{ }^{\circ} \mathrm{C}$. Figure 6-(b) shows the temperature history of concrete at the hot surface $(x=0)$ of the specimen. The temperature $(T)$ and pressure $(p)$ were measured throughout the 113.65-minute duration of the experiment. Measuring positions were at 5 distances from the hot surface, as shown in Fig. 6-(a).

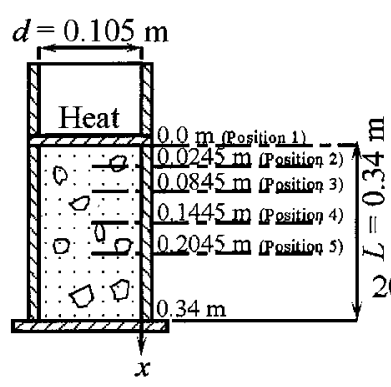

(a) Specimen



(b) Temperature history
Figure 6 Test specimen and temperature history of concrete at the hot surface $(x=0)$ (Khan [14], [15]).

Table 3 Mix proportions of Concrete (Khan [14], [15]).

\begin{tabular}{l|c|c|c|c|c|}
\hline $\begin{array}{c}\text { Cement } \\
(\mathrm{SRPC})^{* 1}\end{array}$ & $\begin{array}{c}\text { Cemsave } \\
(\mathrm{BFS})^{* 2}\end{array}$ & Sand $*^{3}$ & $\begin{array}{c}\text { Coarse } *^{4} \\
\text { aggregate }\end{array}$ & Water & $\begin{array}{c}\text { Plasticiser } \\
(\text { Cormix P1) }\end{array}$ \\
\hline 0.5 & 0.5 & 1.46 & 2.51 & 0.39 & 0.0057 \\
\hline
\end{tabular}
Water/cement ratio $(w / c)=0.39$.
Aggregate/cement ratio $(a / c)=3.97$.
*1: SRPC = Sulphate Resisting Portland Cement.
*2: BFS = Blast Furnace Slag.
*3: Calcareous quartz.
*4: Crushed quartz dolerite (Basalt).

In order to simulate Khan's experiment, the specimen is represented by a one-dimensional model of length $L=0.34$ $\mathrm{m}$. Both the hot surface $(x=0)$ and the cold surface $(x=L)$ are sealed. The input data for the numerical analysis are shown in Table 4.

Table 4 Input data for numerical analysis.

\begin{tabular}{|l|l|}
\hline \multicolumn{2}{|c|}{ Initial conditions } \\
\hline Mass of chemically-bound water $\left(m_{\mathrm{nw}}\right)$ & $71.1 \mathrm{~kg} \mathrm{~m}^{-3}$ \\
\hline Mass of gel water $\left(m_{\mathrm{gw}}\right)$ & $64.9 \mathrm{~kg} \mathrm{~m}^{-3}$ \\
\hline Mass of free water $\left(m_{\mathrm{fw}}\right)$ & $43.9 \mathrm{~kg} \mathrm{~m}^{-3}$ \\
\hline Volume of pores $\left(V_{\mathrm{p}}\right)$ & $0.0841 \mathrm{~m}^{3} \mathrm{~m}^{-3}$ \\
\hline \multicolumn{2}{|c|}{ Properties of concrete } \\
\hline Permeability $(k) \quad$ & $1.0 \times 10^{-16} \mathrm{~m}^{2}$ \\
\hline
\end{tabular}


Figure 7 compares simulated and experimental pressure distributions in the concrete specimen at various heating times. After heating, pressure increases with time and there are pressure gradients in the hot region; however, pressure distribution gradually becomes uniform with time. Numerical results qualitatively simulate these phenomena well.

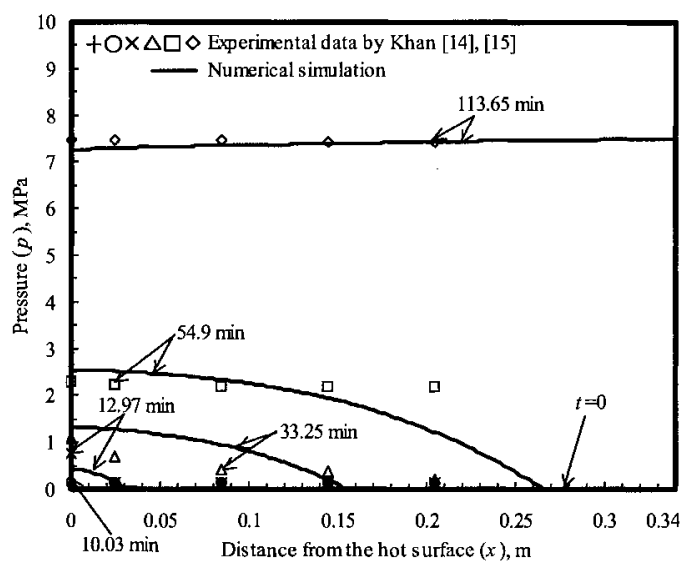

Figure 7 Comparison of simulated and experimental pressure distributions at various times.

Figure 8 compares simulated and experimental pressure-temperature relationships at the 5 different positions of the concrete specimen. The agreement between numerical simulation and experimental data is qualitatively good. The figure infers that rapid moisture migration occurs close to the hot surface (positions 1 and 2), and pressures there fall below the saturation vapour pressure $\left(p_{\text {svp }}, T\right)$ after as little as 10 minutes from the start of heating. Thereafter, pressures increase as temperature rises, but always remain below the saturation vapour pressure. However, pressures at positions 3,4 and 5 are always above the saturation vapour pressure. Therefore, these positions are in the saturated zone during the experiment.

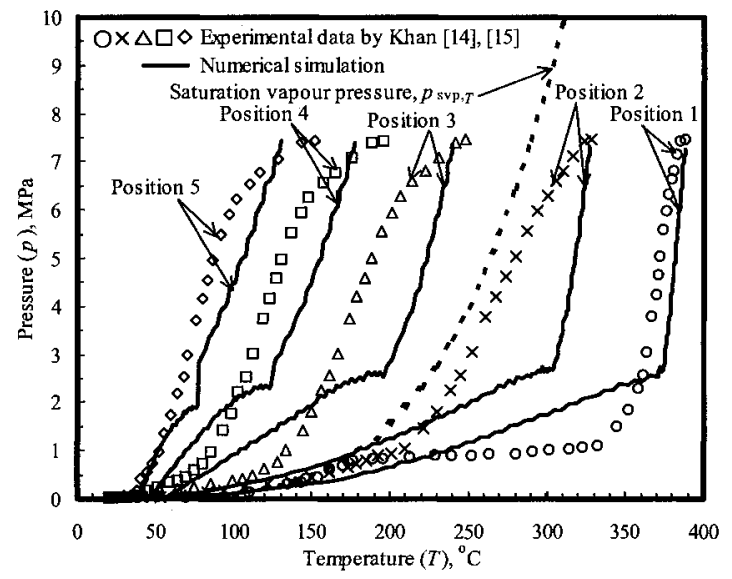

Figure 8 Comparison of simulated and experimental pressure - temperature relationships at 5 positions.

\section{PREDICTION OF CONCRETE SPALLING}

When concrete is subjected to rapid heating at high temperatures as in a fire, spalling can occur. Spalling is a failure phenomenon that leads to local breakdown and removal of surface material, sometimes with explosive violence. The primary cause of spalling is regarded here as the build-up of pore pressure at high temperatures. The pore pressures in heated concrete increase because of the existence of water in the pores. When the tensile stress due to pore pressure exceeds the tensile strength of the concrete, spalling is assumed to occur.

In order to simulate concrete spalling behaviour, a numerical analysis is performed. A concrete wall is represented by a one-dimensional model of length $L$, as shown in Fig. 9-(a). Both the hot surface $(x=0)$ and the cold surface $(x=L)$ are unsealed. The wall is heated by fire on one surface only. The input data for the numerical analysis are shown in Table 5.

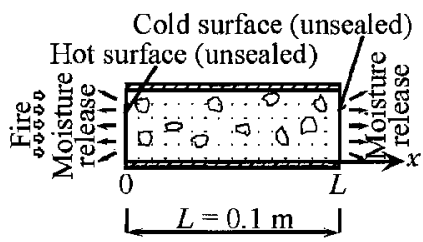

(a) One-dimensional model

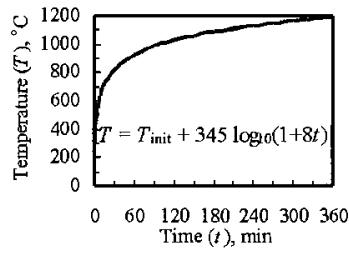

(b) Fire temperature
Figure 9 Modelling of a concrete wall.
Table 5 Input data for numerical analysis.

\begin{tabular}{|l|l|}
\hline \multicolumn{2}{|c|}{ Initial conditions } \\
\hline Mass of chemically-bound water $\left(m_{\mathrm{nw}}\right)$ & $46.0 \mathrm{~kg} \mathrm{~m}^{-3}$ \\
\hline Mass of gel water $\left(m_{\mathrm{gw}}\right)$ & $42.0 \mathrm{~kg} \mathrm{~m}^{-3}$ \\
\hline Mass of free water $\left(m_{\mathrm{fw}}\right)$ & $12.0 \mathrm{~kg} \mathrm{~m}^{-3}$ \\
\hline Volume of pores $\left(V_{\mathrm{p}}\right) \quad$ Properties of concrete \\
\hline \multicolumn{2}{|c|}{$0.050 \mathrm{~m}^{3} \mathrm{~m}^{-3}$} \\
\hline Permeability $(k) \quad$ & $1.0 \times 10^{-18} \mathrm{~m}^{2}$ \\
\hline
\end{tabular}

Hydrated-cement/water ratio $\left(\alpha_{\mathrm{h}} /(w / c)\right)=2.0$.

Temperature (Fig. 10)

The temperature at the hot surface $(x=0)$ rapidly rises with time. The increase in face temperature causes a temperature rise within the concrete wall. 


\section{Moisture content (Fig. 11)}

The moisture content near the hot surface rapidly decreases, since moisture is released from the hot surface into the environment due to pressure-induced flow. Accordingly, the region near the hot surface becomes a dry zone. Moisture also moves towards the cold surface. Therefore, moisture content in the wet zone existing on the right side of the dry zone gradually increases. Once the moisture content in the wet zone reaches the moisture content for saturated liquid water $\left(m_{\mathrm{sat}, T}\right)$, which is the maximum moisture content for maintaining the wet zone, a saturated zone is produced between wet zone 1 and wet zone 2. This point is plotted as point $\mathrm{S} 1$. The time $\left(t_{\mathrm{S} 1}\right)$, location $\left(x_{\mathrm{S} 1}\right)$ and moisture content $\left(m_{\mathrm{S} 1}\right)$ at point $\mathrm{S} 1$ are 375 $\mathrm{s}, 0.004 \mathrm{~m}$ and $81.4 \mathrm{~kg} \mathrm{~m}^{-3}$, respectively. Moisture flow in the saturated zone is restricted, since the pore volume is filled with liquid water only. In the saturated zone, moisture flow is constant, and moisture content is equal to or slightly greater than the moisture content for saturated liquid water $\left(m_{\text {sat } T}\right)$. The zones (i.e. dry, wet 1 , saturated and wet 2$)$ and the moving-interfaces (i.e. $X_{\mathrm{D}-\mathrm{W}_{1}}, X_{\mathrm{W} 1-\mathrm{S}}$ and $X_{\mathrm{S}-\mathrm{W}_{2}}$ ) between these zones at $t=30 \mathrm{~min}$ are shown in Fig. 11. These moving-interfaces move to the right with time. At $t=2170 \mathrm{~s}$ $\left(=t_{\mathrm{S} 2}\right)$, the right side of the saturated zone reaches the cold surface (at $x=L$ ), and wet zone 2 disappears. This point is plotted as point $\mathrm{S} 2$.

\section{Pressure (Fig. 12)}

Pressure increases with time due to rising temperatures and increasing moisture content. The zones (i.e. dry, wet 1 , saturated and wet 2) for $t=30 \mathrm{~min}$ are shown in Fig. 12. In the wet zone, the pressure equals the saturation vapour pressure $\left(p_{\mathrm{svp}, T}\right)$. In the saturated zone, the state of free water is compressed water, i.e. excess mass of water is present, over and above that which is required to just saturate the pores at the saturation vapour pressure at the local temperature. The pressure in the saturated zone is thus higher than the saturation vapour pressure.

\section{Tensile Stress (Figs. 13 and 14)}

The distributions and histories of tensile stress $\left(\sigma_{t}\right)$ are shown in Figs. 13 and 14, respectively. Tensile stress $\left(\sigma_{t}\right)$ is a function of pressure $(p)$ and pore volume $\left(V_{\mathrm{p}}\right)$ (see APPENDIX). The tensile stress distributions are similar in shape to the pressure distributions. The maximum tensile stress curves are plotted in Figs. 13 and 14.

\section{Mass of Lost Water (Fig. 15)}

The mass of lost water at $x=0$ increases with time because water is mainly lost from the hot surface into the environment in the early stages of heating. The mass of lost water at $x=L$ is very small in the early stages of heating. However, after $t=t_{\mathrm{S} 2}$ (point S2), at which the saturated zone reaches the cold surface, the mass of lost water at $x=L$ rapidly increases with time. After $30 \mathrm{~min}$ of heating, the concrete wall lost $8 \%$ of its total mix water. After $60 \mathrm{~min}$ of heating, the concrete wall lost $43 \%$ of its total mix water.

\section{Moving-Interface (Fig. 16)}

The relationships between the location and time for the moving-interfaces are plotted in Fig. 16. Moving-interfaces $X_{\mathrm{D}-\mathrm{W} 1}$ and $X_{\mathrm{W} 1-\mathrm{W} 2}$ move to the right. When movinginterface $X_{\mathrm{W} 1-\mathrm{W} 2}$ reaches point $\mathrm{S} 1$, at which a saturated zone appears for the first time, it separates into moving-interface $X_{\mathrm{W} 1-\mathrm{S}}$ and moving-interface $X_{\mathrm{S}-\mathrm{W} 2}$. After $t=t_{\mathrm{S} 1}$ (point S1) each moving-interface moves to the right. The length of the dry zone, which is sandwiched between the hot surface $(x=0)$ and moving-interface $X_{\mathrm{D}-\mathrm{W} 1}$, increases with time. Moving-interface $X_{\mathrm{S}-\mathrm{w} 2}$ moves faster than moving-interface $X_{\mathrm{W} 1-\mathrm{S}}$ because the moisture transfer rate across $X_{\mathrm{W} 1-\mathrm{S}}$ is greater than that across $X_{\mathrm{S}-\mathrm{W} 2}$. Therefore, the length of the saturated zone, which is sandwiched between movinginterfaces $X_{\mathrm{W} 1-\mathrm{s}}$ and $X_{\mathrm{S}-\mathrm{W} 2}$, increases. The length of wet zone 2 , which is sandwiched between moving-interface $X_{S}$ $\mathrm{w}_{2}$ and the cold surface $(x=L)$, decreases, and wet zone 2 disappears at $t=t_{\mathrm{S} 2}$ (point S2), at which moving-interface $X_{\mathrm{S} \text { - }}$ $w_{2}$ reaches the cold surface. After $t=t_{\mathrm{S} 2}$, the length of the dry zone increases and the length of the saturated zone decreases.

\section{Relationships between Pressure and Temperature (Fig.} 17)

Pressure $(p)$ at each location increases as temperature $(T)$ rises. Each curve has a pressure peak with respect to an increase in temperature. These peaks correspond to point $\mathrm{S} 2$. After $t=t_{\mathrm{S} 2}$ (point S2), a great deal of water is released from the cold surface and pressure in the concrete wall gradually decreases with time everywhere. The figure infers that rapid moisture loss occurs close to the hot surface $(x=0.005 \mathrm{~m})$ and pressures there fall below the saturation vapour pressure $\left(p_{\mathrm{svp}, T}\right)$ after as little as 10 minutes from the start of heating. Thereafter, pressure at $x=0.005 \mathrm{~m}$ increases as temperature rises but always remains below the saturation vapour pressure. However, pressure at $x=0.08 \mathrm{~m}$ is never less than the saturation vapour pressure. Pressures at the other positions (i.e. $x=0.01,0.02,0.05 \mathrm{~m}$ ) become higher than the saturation vapour pressure $\left(p_{\mathrm{svp}, T}\right)$ during heating, and then, fall below $p_{\text {svp }, T}$ with time as drying penetrates deeper into the concrete.

\section{Prediction of Concrete Spalling}

When the calculated tensile stress $\left(\sigma_{t}\right)$ exceeds the concrete tensile strength $\left(f_{t}\right)$, spalling occurs. The location, time and temperature at which spalling occurs can be predicted. The spalling point for concrete with nominal tensile strength of $5 \mathrm{MPa}$ is plotted as point SP in Figs. 10 to 17 . The location $\left(x_{\mathrm{SP}}\right)$, time $\left(t_{\mathrm{SP}}\right)$ and temperature $\left(T_{\mathrm{SP}}\right)$ at which concrete spalls are $0.010 \mathrm{~m}, 786 \mathrm{~s}$ and $291{ }^{\circ} \mathrm{C}$, respectively. 


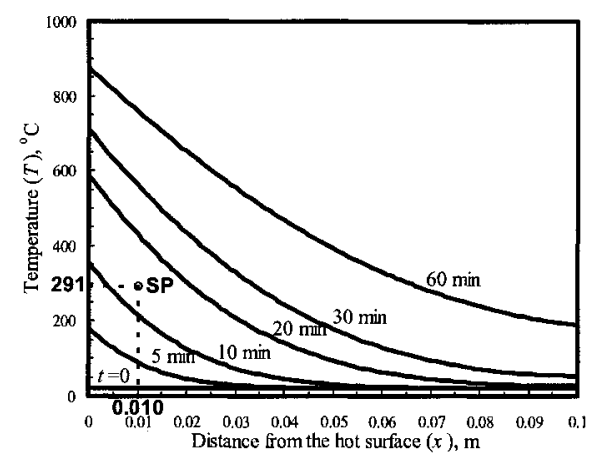

Figure 10 Temperature distributions at various times.

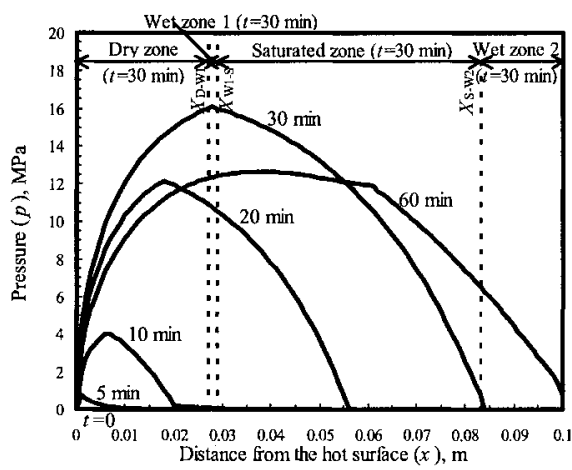

Figure 12 Pressure distributions at various times.

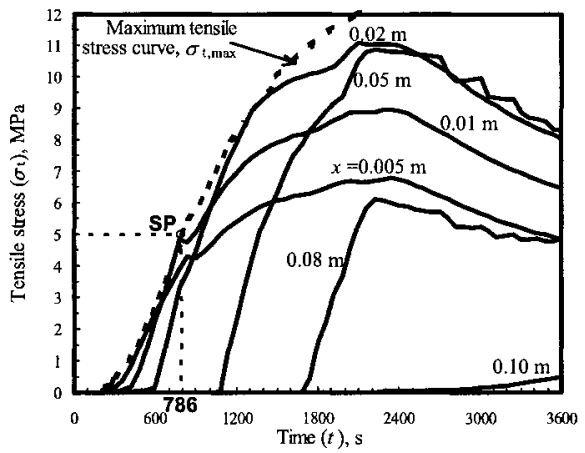

Figure 14 Tensile stress histories at different distances.



Figure 16 Changes in location of moving-interfaces with time. Figure 17 Relationships between pressure and temperature at different distances.

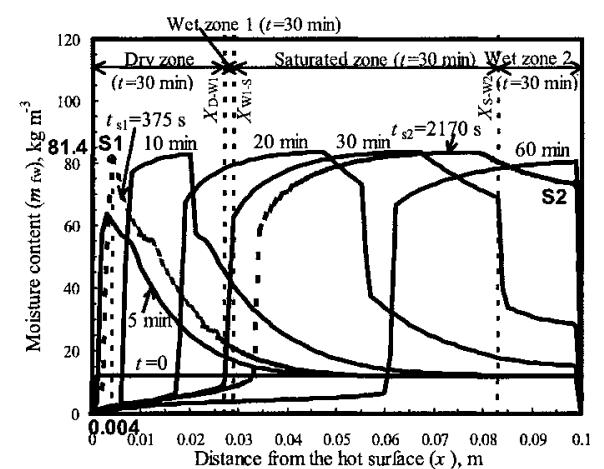

Figure 11 Moisture content distributions at various times.



Figure 13 Tensile stress distributions at various times.

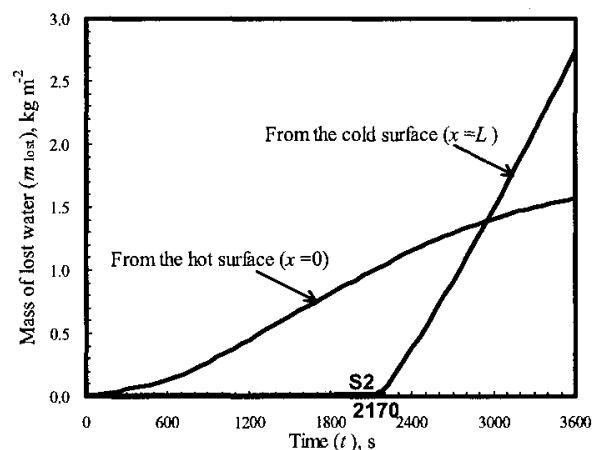

Figure 15 Histories of mass of water lost from the surfaces.

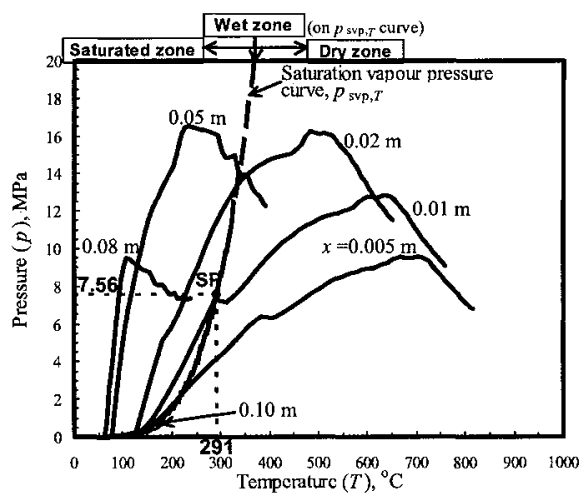




\section{SUMMARY AND CONCLUSION}

A mathematical and computational model has been set up to predict heat and moisture transfer and pore pressures in concrete at high temperatures. Numerical analyses have been performed for (1) simulation of long-term moisture migration, (2) simulation of short-term pressure build-up and (3) prediction of concrete spalling during a fire. The numerical results have revealed complicated interactions between temperature, moisture content and pore pressure, yet have produced realistic predictions. The numerical methodology in this paper thus provides a tool for the simulation of both short- and long-term heating effects in concrete.

\section{REFERENCES}

1. Bazant, Z. P. and Thonguthai, W., "Pore pressure and drying of concrete at high temperature," Journal of Engineering Mechanics Division, Proceedings of the American Society of Civil Engineers, Vol. 104, 1978, pp. 1059-1079.

2. Bazant, Z. P. and Thonguthai, W., "Pore pressure in heated concrete walls: theoretical prediction," Magazine of Concrete Research, Vol. 31, 1979, pp. 6776.

3. Ahmed, G. N. and Hurst, J. P., "Modeling the thermal behavior of concrete slabs subjected to the ASTM E119 standard fire condition," Journal of Fire Protection Engineering, Vol. 7, 1995, pp. 125-132.

4. Ahmed, G. N. and Hurst, J. P., "Coupled heat and mass transport phenomena in siliceous aggregate concrete slabs subjected to fire," Fire and Materials, Vol. 21, 1997, pp. 161-168.

5. Ahmed, G. N. and Hurst, J. P., "An analytical approach for investigating the causes of spalling of high-strength concrete at elevated temperatures, International Workshop on Fire Performance of High-Strength Concrete," NIST Special Publication 919, Phan, L.T., Carino, N.J., Duthinh, D. and Garboczi, E. eds., National Institute of Standards and Technology, Gaithersburg, Maryland, pp. 95-108, 1997.

6. England, G. L. and Khoylou, N. "Pore pressures and moisture flow in concrete: steady and transient temperatures," Transactions of the 14th International Conference on Structural Mechanics in Reactor Technology, Vol. 5, Division H, pp. 491-501, Lyon, France, 1997.

7. Khoylou, N., Modelling of Moisture Migration and Spalling Behaviour in Non-uniformly Heated Concrete, Ph.D. Thesis, Imperial College, University of London, 1997.

8. Ichikawa, Y., Prediction of Pore Pressures, Heat and Moisture Transfer Leading to Spalling of Concrete during Fire, Ph.D. Thesis, Imperial College, University of London, 2000.

9. Saul, A. and Wagner, W., "International equations for the saturation properties of ordinary water substance," Journal of Physical and Chemical Reference Data, Vol. 16, 1987, pp. 893-901.

10. Saul, A. and Wagner, W., "A fundamental equation for water covering the range from the melting line to 1273
$\mathrm{K}$ at pressures up to $25000 \mathrm{MPa}$," Journal of Physical and Chemical Reference Data, Vol. 18, 1989, pp. 15371564.

11. Sengers, J. V. and Watson, J. T. R., "Improved international formulations for the viscosity and thermal conductivity of water substance," Journal of Physical and Chemical Reference Data, Vol. 15, 1986, pp. 12911314.

12. Chapman, D. A., A Study of the Movement of Moisture in and from Concrete at Elevated and Non-uniform Temperatures, Ph.D. Thesis, King's College, University of London, 1976.

13. Chapman, D. A. and England, G.L., "Effects of moisture migration on shrinkage, pore pressure and other concrete properties," Transactions of the 4th International Conference on Structural Mechanics in Reactor Technology, Paper H5/3, San Francisco, 1977.

14. Khan, S. A., Pore Pressure and Moisture Migration in Concrete at High and Non-uniform Temperatures, Ph.D. Thesis, King's College, University of London, 1990.

15. England, G. L., Greathead, R.J. and Khan, S.A., "Influence of high temperature on water content, permeability and pore pressures in concrete," Transactions of the 11th International Conference on Structural Mechanics in Reactor Technology, Vol. H, pp. 31-36, Tokyo, Japan, 1991.

\section{APPENDIX Tensile Stress of Concrete}

A concrete skeleton is approximated by a hollow spherical model to estimate concrete tensile stress. Concrete tensile stress $\left(\sigma_{t}\right)$ is then a function of pore pressure $(p)$ and pore volume $\left(V_{\mathrm{p}}\right)$ as shown in Fig. 18.

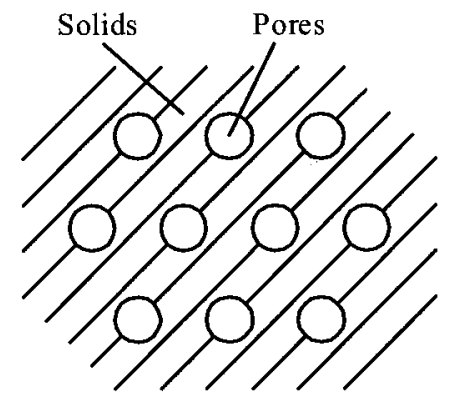

(a) Concrete skeleton

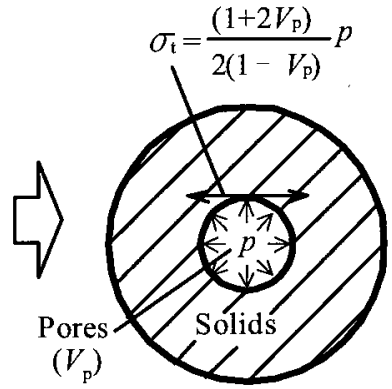

(b) Tensile stress
Figure 18 Tensile stress of a hollow spherical model. 